\title{
Evolution of HCV-Associated Cryoglobulinemic Vasculitis after Treatment with Direct-Acting Antivirals
}

\author{
Andreea Franculescu-Bertea*, Ionel Copaci, Laura Iliescu, Laurentiu Micu
}

*Corresponding author: Andreea Franculescu-Bertea, MD Department of Internal Medicine Fundeni Clinical Institute, Bucharest Romania

E-mail: a.franculescu1989@gmail.com

Received: 23.07.2021

Accepted: 27.09.2021

$\overline{\text { Copyright } \odot \text { Celsius Publishing House }}$ www.sgo-iasgo.com
Department of Internal Medicine, Fundeni Clinical Institute, Bucharest, Romania

\section{ABSTRACT}

Background: Circulating cryoglobulins are detected in $40-60 \%$ of patients with HCV chronic infection, and cryoglobulinemic vasculitis is observed in $15 \%$ of cases.

Methods: We included 24 patients with HCV-related mixed cryoglobulinemia (MC) and 8 patients with asymptomatic HCV cryoglobulinemia, between 2016-2019. All patients received DAA therapy: 22 patients with ombitasvir/paritaprevir/ritonavir and dasabuvirand 10 patients with ledipasvir/sofosbuvir. The primary endpoint was complete clinical remission of vasculitis at week 24.

Results: All 5 patients with renal involvement received immunosuppressive therapy; complete clinical remission occurred in 3 of these cases. SVR was achieved in $91.6 \%$ of patients with vasculitis, compared to $100 \%$ in the asymptomatic group $(p=0.01)$. Purpura, myalgia, arthralgia and muscular weakness resolved in $91.6 \%$ of patients after SVR. Neurological symptoms improved in $75 \%$ of cases. All immunological parameters improved after therapy. Circulating cryoglobulins became undetectable in $54.2 \%$ of patients with vasculitis and in $62.4 \%$ of the asymptomatic group. The predictive factors for clinical and immunological response were: level of fibrosis, cryocrit and C4 levels, rheumatoid factor activity, and BVASv3.

Conclusions: Direct antiviral therapy generates a virological response of over $95 \%$ in patients with HCV cryoglobulinemic vasculitis, and is associated with increased rates of complete clinical response and moderate immunological response.

Key words: cryoglobulins, vasculitis, hepatitis C virus, direct-acting antivirals

\section{INTRODUCTION}

Mixed circulating cryoglobulins are detected in $40-60 \%$ of patients with chronic hepatitis C virus (HCV) infection, while cryoglobulinemic vasculitis is observed in $15 \%$ of cases. Prognosis is variable, and depends on the degree of renal injury or the extent of vasculitic lesions $(1,2)$.

Patients with mild or moderate forms of HCV-associated glomerulonephritis (stable renal function and/or non-nephrotic proteinuria) should be treated with direct-acting antivirals (DAAs).

In patients with HCV-associated renal disease with resistance to DAA therapy, immunosuppressive therapy should be associated. 
The DAA regimens which are used are very efficient, with an SVR rate of around 95\%, and with adverse effects occurring in less than $10 \%$ of cases (3).

Treatment of HCV vasculitis is difficult. Sustained virological response is the main goal in these patients, because clinical remission of vasculitis is closely linked to viral clearance. Studies regarding treatment with direct antivirals have shown a remarkable eradication rate, of $90-100 \%$, depending on HCV genotype $(4,5)$.

The use of ledipasvir/sofosbuvir should be avoided in the treatment of patients with cryoglobulinemic nephropathy and eGFR $\leq 30 \mathrm{ml} / \mathrm{min}$, due to the risk of accumulation of the active metabolite GS-331007, which deteriorates renal function. In these cases, therapeutic regimens such as ritonavir/paritaprevir/ ombitasvir and dasabuvir (as is the case in our study), elbasvir/grazopevir or glecaprevir/pibrentavir should be used.

\section{MATERIAL AND METHOD}

We included 24 patients with HCV-related mixed cryoglobulinemia (MC)in a prospective study, performed in the Internal Medicine Department, Funden Clinical Institute, between 2016-2019. Patients were at least 18 years old, with no upper age limit, and presented active HCV vasculitis, defined by vasculitic lesions of the skin, joints, kidneys, peripheral nerves and/or cerebral, digestive, pulmonary and/or cardiac involvement (Chapel Hill criteria, 2012) (6).

8 patients with asymptomatic HCV cryoglobulinemia were also included.

Exclusion criteria were non-active cryoglobulinemic vasculitis, HIV or HBV infection, decompensated liver cirrhosis.

Clinical evaluation at study entry included age, gender, neurological involvement(peripheral and/or central), skin involvement (Raynaud phenomenon, purpura, distal ulcers, skin necrosis), arthralgia, myalgia, bowel movement disorders, kidney injury (proteinuria, hematuria and glomerular filtration rate) and clinical signs of liver disease.

All patients were evaluated every 4 weeks, up to 24 weeks.

Disease activity and therapeutic response were evaluated using the Birmingham vasculitis activity score (7).

Viral load was determined using Abbot HCV Real Time Assay, with a lower limit of detection of $12 \mathrm{lU} / \mathrm{mL}$. HCV genotyping was performed using the sequence of the NS5b gene. Laboratory evaluation included complete blood count, serological biochemical profile, rheumatoid factor, quantitative IgM, total complement and C4 fraction, cryoglobulins (cryocrit over $1 \%$ in at least 2 determinations and characterization of cryoprecipitate by immunofixation).

Cryoglobulins have been classified by Brouet et al (8) as type II in the presence of monoclonal IgM and policlonal IgG, and as type III in forms with policlonal immunoglobulins.

Liver fibrosis was evaluated by non-invasive methods (fibroscan, fibromax).

All patients were eligible for DAA treatment: 22 patients with ombitasvir/paritaprevir/ritonavir and dasabuvir (3D regimen) and 10 patients with ledipasvir /sofosbuvir (LDV/SOF).

The primary end-point was complete clinical remission of vasculitis at week 24 . Complete clinical response was defined as improvement of the functions of all initially affected organs, and by the absence of clinical relapse.

Skin and joint improvement were evaluated clinically (remission of purpura and/or ulcers; remission of arthralgia or arthritis). Renal injury was evaluated biologically (proteinuria below $0.3 \mathrm{gr} / 24 \mathrm{~h}$, remission of hematuria, and improvement of GFR $>20 \%$ at week 24 , if $\mathrm{GFR}<60 \mathrm{~mL} / \mathrm{min}$ at initiation).

Improvement of peripheral neurological affection was evaluated clinically (improvement of pain and of parestesia using thevisual analogue scale, improvement of muscular contraction and of initial motor affection) and/or electrophysiologically (improvement of electromyogram anomalies at week 24 , compared to the initial aspect). Neuropathy total symptoms score-6 (NTSS-6) was applied for evaluating symptoms of sensory neuropathy.

Partial clinical response at week 24 was defined as an improvement in the functions of some of the initially affected organs. Patients without clinical response at week 24 were defined as therapeutical failure.

Secondary endpoints were:

a. Virological response at week 12 (end of treatment - EOT) and 24 (SVR).

b. Evolution of cryoglobulinemia and of the C4 fraction of the complement.

c. Secondary effects of therapy.

\section{Statistical analysis}

Median and range values were used for relevant variables. The groups were compared using the MannWhitney test for continuous variables, and the Fisher test for categorical variables. The Wilcoxon rank test 
was used for comparing two samples. Logistical regressive analysis was used to identify predictive factors for clinical and immunological response.

\section{RESULTS}

Our study included 32 patients with HCV infection and cryoglobulinemia, who received direct antiviral therapy. The clinical, biochemical and immunological characteristics of patients are presented in table 1. Of the 32 patients, 24 presented characteristics of cryoglobulinemic vasculitis, while 8 had asymptomatic cryoglobulinemia.

By comparing the 2 groups, we remarked the predominance of female gender among patients with vasculitis, as well as lower $\mathrm{C} 4$ levels in this group (0.03 $\mathrm{g} / \mathrm{L}$ vs $0.10 \mathrm{~g} / \mathrm{L}, \mathrm{p}=0.05)$ and higher RF $(96 \mathrm{U} / \mathrm{mL}$ vs 11 $\mathrm{U} / \mathrm{mL} \mathrm{p}=0.01$ ) and cryocrit levels (3.4\% vs $2.3 \%$ ).

Table 1 - Baseline characteristics of the 64 patients included in the study

\begin{tabular}{|c|c|c|c|c|}
\hline Baseline parameters & $\begin{array}{l}\text { All patients } \\
\quad(n=32)\end{array}$ & $\begin{array}{l}\text { Patients with cryoglobulinemic } \\
\text { vasculitis } \\
(\mathrm{n}=24)\end{array}$ & $\begin{array}{l}\text { Asymptomatic patients with } \\
\text { circulating cryoglobulins } \\
\qquad(\mathrm{n}=8)\end{array}$ & $\mathbf{P}$ \\
\hline Age, y & $58(38-76)$ & $57(42-72)$ & $64(56-76)$ & 0.91 \\
\hline Female gender, $\mathrm{n}(\%)$ & $19(59.3 \%)$ & $16(66.6 \%)$ & $3(37.5 \%)$ & 0.04 \\
\hline $\begin{array}{l}\text { Clinical manifestations, n (\%) } \\
\text { Purpura } \\
\text { Arthralgia/arthritis } \\
\text { Weakness } \\
\text { Polyneuropathy } \\
\text { Renal injury } \\
\text { Sicca syndrome } \\
\text { Abdominal involvement } \\
\text { Raynaud phenomen }\end{array}$ & $\begin{array}{c}22(68.7) \\
9(28.1) \\
26(81.2) \\
18(56.2) \\
5(15.6) \\
3(9.3) \\
2(6.2) \\
5(15.5)\end{array}$ & & & \\
\hline Viral parameters & & & & \\
\hline $\begin{array}{l}\text { HCV genotype, } \mathrm{n}(\%) \\
1 \mathrm{a} \\
1 \mathrm{~b} \\
2 \\
3 \\
4\end{array}$ & $\begin{array}{c}3(9.3) \\
29(90.6)\end{array}$ & & - & \\
\hline $\begin{array}{l}\text { Baseline HCV RNA level, } \\
\mathrm{IU} / \mathrm{mL}\end{array}$ & $\begin{array}{c}860.200 \\
(14600-10.880 .000)\end{array}$ & $\begin{array}{c}910.000 \\
(26.860-10.880 .000)\end{array}$ & $\begin{array}{c}210.800 \\
(14.600-630.000)\end{array}$ & 0.02 \\
\hline $\begin{array}{l}\text { General laboratory } \\
\text { ALT level, IU/mL } \\
\text { Platelets, } \times 10^{9} / \mathrm{L} \\
\text { Transient elastography, } \mathrm{kPa}\end{array}$ & $\begin{array}{c}76(41-188) \\
178(108-246) \\
14(9,2-30)\end{array}$ & $\begin{array}{l}81(40-191) \\
127(74-159) \\
19(11,9-37)\end{array}$ & $\begin{array}{l}76(41-153) \\
151(88-176) \\
12,8(8,2-24)\end{array}$ & $\begin{array}{l}0.08 \\
0.05 \\
0.01\end{array}$ \\
\hline $\begin{array}{l}\text { Immunologic parameters } \\
\text { Cryocrit (\%) } \\
\text { C4, g/L } \\
\text { CH 50, IU/mL } \\
\text { Rheumatoid factor, IU/mL }\end{array}$ & $\begin{array}{c}2.5(1.2-5.1) \\
0.07(0.02-0.15) \\
15(11-29) \\
31(10-118)\end{array}$ & $\begin{array}{c}3.4(1.7-5.9) \\
0.03(0.02-0.12) \\
13(11-29) \\
96(10-193)\end{array}$ & $\begin{array}{c}2.3(0.9-3) \\
0.10(0.07-0.19) \\
14(10-25) \\
11(10-26)\end{array}$ & $\begin{array}{l}0.04 \\
0.03 \\
0.06 \\
0.01\end{array}$ \\
\hline $\begin{array}{l}\text { Treatment, } \mathrm{n}(\%) \\
\text { Naive } \\
\text { Null responder }\end{array}$ & $\begin{array}{l}20 \\
12\end{array}$ & $\begin{array}{l}12 \\
12\end{array}$ & $\begin{array}{l}8 \\
0\end{array}$ & \\
\hline $\begin{array}{l}\text { DAA treatment regimens, } \mathrm{n}(\%) \\
\text { 3D } \\
\text { LDV/SOF }\end{array}$ & $\begin{array}{l}22 \\
10\end{array}$ & $\begin{array}{l}12 \\
10\end{array}$ & 8 & \\
\hline $\begin{array}{l}\text { Use of RBV, } n(\%) \\
\text { SVR } 12\end{array}$ & $(30 / 32) 93.7 \%$ & (22/24) $91.6 \%$ & $(8 / 8) 100 \%$ & 0.01 \\
\hline $\begin{array}{l}\text { Immunosuppressive therapy, } \mathrm{n}(\%) \\
\text { Corticosteroids } \\
\text { Corticosteroids+cyclophosphamide } \\
\text { Plasmapheresis }\end{array}$ & & $\begin{array}{l}8(33.3) \\
4(16.6) \\
3(12.5)\end{array}$ & & \\
\hline $\begin{array}{l}\text { Liver fibrosis, } n(\%) \\
\quad F_{1} \\
F_{2} \\
F_{3} \\
F_{4}\end{array}$ & $\begin{array}{l}4(12.6) \\
5(15.6) \\
7(21.8) \\
16(50)\end{array}$ & $\begin{array}{c}2(8.3) \\
2(8.3) \\
5(20.8) \\
15(62.6)\end{array}$ & $\begin{array}{c}2(25 \%) \\
3(37.5 \%) \\
2(25 \%) \\
1(12.5 \%)\end{array}$ & \\
\hline
\end{tabular}


The main clinical manifestations of cryoglobulinemic vasculitis were: purpura (68.7\%), arthralgia/arthritis (28.1\%), weakness $(81.2 \%)$, polyneuropathy $(56.2 \%)$, and kidney injury (15.6\%).

One of the 5 patients with kidney injury received immunosuppressive therapy associated with plasma exchange. Complete clinical remission was obtained in 3 cases $(60 \%)$, with a significant improvement of kidney failure (creatinine clearance $>60 \mathrm{~mL} / \mathrm{min}$ ) and with SVR at 12 weeks, in all 3 cases. Nephrotic syndrome and creatinine clearance did not improve significantly in one patient, while the fifth patient presented an improvement of proteinuria ( $<1 \mathrm{gr} / 24 \mathrm{hrs}$ ) and of creatinine clearance (from 34 to $55 \mathrm{~mL} / \mathrm{min}$ ).

16 of 18 patients with neurological symptoms were evaluated by electromyography, which confirmed peripheral polyneuropathy: 6 with neuropathy multiplex, 7 with sensory polyneuropathy, and 3 with sensorimotor polyneuropathy.

Kidney biopsy was performed in all 5 patients with kidney injury, and confirmed membrano-proliferative glomerulonephritis, 3 of these patients being on treatment with glucocorticoid plus monthly cyclophosphamide pulse therapy, while 2 were receiving only glucocorticoid.

Plasma exchange was performed in 3 patients, one with kidney injury and 2 with neuropathy multiplex.

All patients presented type 2 cryoglobulins (polyclonal IgG/monoclonal IgM).

$81.2 \%$ ( 26 of 32 ) of patients presented a decrease of $\mathrm{C} 4$ and of $\mathrm{CH} 50$ activity, and all patients with vasculitis were positive for rheumatoid factor.

SVR at 12 weeks after the end of antiviral therapy was obtained in $91.6 \%$ ( 22 of 24 ) of patients in the vasculitis group, compared to $100 \%$ in the asymptomatic group $(\mathrm{p}=0.01)$.

Purpura, myalgia, arthralgia and muscle weakness remitted in $91.6 \%$ of patients after SVR; of the 5 patients with kidney injury, 4 obtained remission with the resolution of nephrotic syndrome and improvement of glomerular filtration rate (43 vs $57 \mathrm{~mL} / \mathrm{min}$ $\left./ 1.73 \mathrm{~m}^{2}\right)$.

Neurological symptoms improved in $75 \%$ of cases. 3 patients with sicca syndrome and 2 with intestinal involvement were asymptomatic at the end of the follow-up period.

Clinical improvement was also documented by the statistically significant decrease of BVASvs 3 from a mean initial value of 8 points (3-27) to a value of 3 points (0-11), $p<0.001$.

All immunological parameters improved at 12 weeks after the end of therapy. Circulating cryoglobu-

Table 2 - Clinical, biological and immunological evolution after antiviral therapy

\begin{tabular}{|c|c|c|c|c|c|c|}
\hline & \multicolumn{3}{|c|}{ Cryoglobulinemic vasculitis $n=24$} & \multicolumn{3}{|c|}{ Asymptomatic patients $\mathrm{n}=8$} \\
\hline & Pretreatment & Posttreatment & $\mathbf{P}$ & Pretreatment & Posttreatment & $\mathbf{P}$ \\
\hline SVR & & $93.7 \%$ & & & $100 \%$ & \\
\hline Cryoglobulin (n, \%) & $24(100)$ & $11(45.8)$ & 0.001 & $8(100)$ & $3(37.5)$ & 0.001 \\
\hline Cryocrit (\%) & $3.4(1.7-5.9)$ & $0.3(0-1.5)$ & 0.01 & $2.3(0.9-3)$ & $0.1(0-1.1)$ & 0.01 \\
\hline Decrease of C4 $(n, \%)$ & $20(83.3 \%)$ & $5(20.8 \%)$ & 0.001 & $6(75 \%)$ & $3(37.5 \%)$ & 0.001 \\
\hline Decrease of C4 fraction, $\mathrm{g} / \mathrm{L}$ & $\begin{array}{c}0.03 \\
(0.02-0.12)\end{array}$ & $\begin{array}{c}0.14 \\
(0.09-0.19)\end{array}$ & 0.01 & $\begin{array}{c}0.10 \\
(0.07-0.19)\end{array}$ & $\begin{array}{c}0.14 \\
(0.07-0.20)\end{array}$ & 0.02 \\
\hline Decrease of $\mathrm{CH} 50 \mathrm{U} / \mathrm{mL}$ activity $(\mathrm{n}, \%)$ & $19(79.1 \%)$ & $8(33.3 \%)$ & 0.001 & $6(75 \%)$ & $2(25 \%)$ & 0.001 \\
\hline $\mathrm{CH} 50 \mathrm{U} / \mathrm{mL}$ activity & $13(11-29)$ & $36(22-51)$ & 0.01 & $14(10-25)$ & $33(15-47)$ & 0.01 \\
\hline Positive rheumatoid factor $(\mathrm{n}, \%)$ & $17(70.8 \%)$ & $11(45,8 \%)$ & 0.001 & $4(50 \%)$ & $2(25 \%)$ & 0.01 \\
\hline Rheumatoid factor level UI/mL & $96(10-193)$ & $26(11-89)$ & 0.01 & $11(10-26)$ & $10(10-14)$ & 0.03 \\
\hline ALT & $81(46-191)$ & $25(18-30)$ & 0.01 & $76(41-153)$ & $21(16-28)$ & 0.01 \\
\hline Platelets $\times 10^{9} /$ & $127(74-159)$ & $149(91-210)$ & 0.21 & $151(88-186)$ & $152(90-196)$ & 0.98 \\
\hline $\mathrm{GFR} \mathrm{ml} / \mathrm{min} / 1.73 \mathrm{~m}^{2}$ & $93(62-93)$ & $94(65-94)$ & 0.20 & & & \\
\hline \multicolumn{7}{|l|}{ Clinical manifestations (n, \%) } \\
\hline Purpura & $22(68.7)$ & $1(4.1)$ & 0.01 & & & \\
\hline Arthralgia & $9(28.1)$ & $1(4.1)$ & 0.01 & & & \\
\hline Weakness & $26(81.2)$ & $2(8.3)$ & 0.01 & & & \\
\hline Polyneuropathy & $18(56.2)$ & $6(25)$ & 0.01 & & & \\
\hline Neural affection & $5(15.6)$ & $1(4.1)$ & 0.01 & & & \\
\hline Hematuria & $5(15.6)$ & $1(4.1)$ & 0.01 & & & \\
\hline 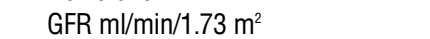 & $43(40-47)$ & $57(42-61)$ & 0.02 & & & \\
\hline Proteinuria g/L & $1.7(1.1-2.1)$ & $0.32(0.1-1.9)$ & 0.62 & & & \\
\hline BV AS & $9(4-18)$ & $0(0-5)$ & 0.01 & & & \\
\hline
\end{tabular}


lins became undetectable in $54.2 \%$ of patients with vasculitis and in $62.4 \%$ of patients from the asymptomatic group.

Post-therapeutical normalization of $\mathrm{CH} 50, \mathrm{C} 4$ and RF levels was obtained in $79.2 \%, 66.7 \%$ and $54.2 \%$ respectively in the vasculitis group, compared to $64.5 \%$, $75 \%$ and $75 \%$ respectively in the asymptomatic group.

Most of the patients with immunological response (19 pts, representing 79.1\%) presented an improvement of clinical manifestations.

Predicitve factors for clinical and immunological response, as shown by logistic regression analysis, were: degree of fibrosis, cryocrit level, C4 level, RF activity and BVASv3 (table 3).

The patients included in our study presented the following comorbidities: essential arterial hypertension in 4 cases, renal parenchymal hypertension in 3 patients with cryoglobulinemic chronic glomerulonephritis, chronic bronchitis in one patient, type 2 insulin dependent diabetes mellitus in 1 case, and minor depressive disorder in one case. Arterial hypertension was treated with calcium channel blockers (amlodipine), sartans (irbesartan), beta-blockers (metoprolol) and loop diuretics (furosemide), drugs that have minor interactions with the antiviral medication. The depressive disorder was treated with benzodiazepines (lorazepam $2 \mathrm{mg})$. Patients with arthralgia/arthritis received intermittent treatment with non-steroidal anti-inflammatory drugs (diclofenac $50-100 \mathrm{mg} /$ day).

The patients with these comorbidities presented a favorable clinical, virological and immunological evolution.

\section{DISCUSSIONS}

$\mathrm{HCV}$ cryoglobulinemic vasculitis is a severe disease and a difficult-to-treat entity, with a 10-year mortality rate of $40 \%$, and with a 35 -fold increase in the risk of non-Hodgkin lymphoma, compared to the general population. The main manifestations of HCV cryoglobulinemic vasculitis include purpura and peripheral neuropathy (68.7\%), arthralgia/arthritis (28.1\%), kidney injury (15.6\%), Raynaud phenomenon (15.5\%). (9)

Sustained virological response at 12 weeks from the end of treatment with direct antivirals was $91.6 \%$, while complete clinical remission in patients with vasculitis was $91.6 \%$. (5)

In the VASCUVALDIC study, which enrolled 24 patients with HCV cryoglobulinemic vasculitis, treated with sofosbuvir and ribavirin, complete clinical response at week 24 was $87.5 \%$. (10)

In comparison, treatment with peginterferon and ribavirin, and subsequently with first-generation protease inhibitors, showed a response rate of under $30 \%$, as well as very frequent adverse effects. $(11,12)$

In our study, treatment with ombitasvir/ritonavir/ paritaprevir (viekirax) plus dasabuvir (exviera) - 22 pts, and with sofosbuvir/ledipasvir (harvoni) - 10 pts, determined an SVR rate of $91.6 \%$ in patients with cryoglobulinemic vasculitis and of $100 \%$ in patients with asymptomatic cryoglobulinemia. The favorable virological evoluton was associated with a favorable clinical evolution. The five patients with kidney injury were also treated with immunosuppressive medication (corticosteroids, cyclophosphamide).

Almost all studies have shown that a complete or partial reduction of clinical symptoms, during and after administration of DAAs, was correlated with SVR. A complete clinical response was defined as an improvement of all affected organs and/or a Birmingham vasculitis activity score (version 3 ) of 0 . The best response rate was reported in the prospective study performed by Saadoun et al (13), in which all patients (41 cases) presented SVR, as well as complete and partial clinical response rates of $90 \%$ and $10 \%$, respectively, after 12 or 24 weeks of sofosbuvir/daclatasvir.

Similar results were reported in the study published by Gragnani et al (14), in which $93 \%$ of patients ( 41 of 44) presented a complete or partial response of vasculitis, with an SVR rate of $100 \%$.

However, Sollima et al (15) reported that patients with cryoglobulinemic vasculitis treated with DAAs and who obtained SVR, may present the persistance of symptoms or may relapse. Moreover, this study

Table 3 - Main characteristics associated with complete immunological response

\begin{tabular}{|c|c|c|c|c|}
\hline Variable & Universal analysis OR (95\% CI) & $\mathbf{P}$ & Multivariable analysis OR (95\% CI) & $\mathbf{P}$ \\
\hline $\mathrm{F} 1-2$ & $0.8(0.21-1.9)$ & 0.05 & & \\
\hline Cryocrit $<2,2 \%$ & $7.2(2.8-21)$ & 0.01 & $9.4(2.8-38)$ & 0.002 \\
\hline $\mathrm{C} 4>0.25 \mathrm{~g} / \mathrm{L}$ & $6.7(2.3-24)$ & 0.03 & $8.2(2.3-31)$ & 0.004 \\
\hline $\mathrm{RF}<20 \mathrm{IU} / \mathrm{L}$ & $1.14(0.87-1.14)$ & 0.07 & & \\
\hline BVAS $<6$ & $3.53(1.18-10.59)$ & 0.027 & $4.68(2.24-11.43)$ & 0.003 \\
\hline
\end{tabular}


suggests that long-term follow-up is necessary, especially in patients with advanced stages of vasculitis, and especially in patients with kidney injury.

Regarding the therapeutical regimens that associate ribavirin (RBV), the rate of cryoglobulin clearance is similar (47\% vs $48 \%)$, but with a lower SVR rate compared to RBV-free regimens.

It has been shown that DAAs reestablish homeostasia of B and T cells (16). However, clinical symptoms of cryoglobulinemic vasculitis have variable remission rates. In our study, purpura, arthritis/arthralgia and polyneuropathy improved in $62.6 \%, 24 \%$ and $31.2 \%$ of cases, respectively. The immunological changes and especially the levels of cryoglobulin after anti-HCV treatment dictate the persistance of vasculitic activity.

In our study, cryocrit level decreased from 3.4 (1.7-5.9) before therapy to 0.3 (0-1.5) post-therapy.

Bonacci et al (17) found that a baseline cryocrit below $2.7 \%$ is independently associated with complete immunological response, defined as the absence of circulating cryoglobulins and normalization of complement and/or RF levels. Similarly, our study showed that the decrease of cryocrit levels below 2.2\% correlated with a favorable clinical evolution and normalization of complement activity. Normalization of complement activity was observed in $66.7 \%$ of cases, and was accompanied by normalization of the $\mathrm{C} 4$ fraction of the complement in $79.2 \%$ and with the disappearance of RF in $54.2 \%$ of cases.

The pathogenic mechanism for the persistance of cryoglobulin production and of its clinical manifestations, after HCV clearance, is unclear. In cryoglobulinemic vasculitis, B cell proliferation may enter an independent, autonomous phase, as shown by the persistance of $t$ mutation (14:18) in B cell clones, and the presence of small amounts of HCV-RNA in the lymphatic system after obtaining SVR $(18,19)$. Patients who still present manifestations of cryoglobulinemic vasculitis after HCV clearance should be followed-up, due to the increased risk of B cell NHL $(20,21)$.

Regarding kidney injury in cryoglobulinemic vasculitis, it is considered a life-threatening complication.

Before the introduction of DAAs, treatment relied especially on PegIFN and immunosuppressive therapy, with rituximab being the most efficient. In patients treated with first-generation protease inhibitors (telaprevir or boceprevir) plus PegIFN and ribavirin, the use of rituximab was necessary in $43 \%$ of cases, compared to those treated with sofosbuvir and ribavirin, where rituximab was associated in $17 \%$ of cases (10).

In our study, five patients presented histologically documented glomerular injury, with clinical remission and significant improvement of creatinine clearance (>60 mL/min) in $60 \%$ of cases; in these patients, corticosteroids and cyclophosphamide were associated to antiviral therapy, and results were maintained 12 months post-therapy.

Our results indicate the fact that inhibition of viral replication per se is essential for inducing the clinical remission of cryoglobulinemic vasculitis.

Multivariable analysis of the main characteristics associated with complete immunological response revealed the following parameters: cryocrit $<2.2 \%$, $\mathrm{C} 4>0.25 \mathrm{~g} / \mathrm{L}$, and BVAS $<6$.

Adverse effects consisted in fatigue, insomnia, nausea, pruritus, and irritability in $46.8 \%$ of patients. These adverse effects were of low intensity, did not require the interruption of antiviral therapy, and improved under symptomatic medication.

\section{CONCLUSIONS}

Direct interferon-free and ribavirin-free antiviral therapy generates a virological response in over $90 \%$ of patients with HCV cryoglobulinemic vasculitis, and is associated with high rates of complete clinical response, with moderate immunological response and with a low rate of adverse effects.

Our study reveals the importance of initiating treatment in early stages of HCV infection.

\section{Conflict of interest}

The authors declare that they have no conflicts of interests.

\section{Ethical approval}

For performing this study ethical approval was obtained.

\section{REFERENCES}

1. Cacoub P, Camarmond C, Domont F, Savey L, Saadoun D. Cryoglobulinemiavasculitis. Am J Med 2015;128(9):950-5

2. Dammacco F, Sansonno D. Therapy for hepatitis C virus-related cryoglobulinemicvasculitis, N Engl J Med 2013;369(11):1035-45

3. Sneller MC, Hu Z, Langford CA. A randomized controlled trial of rituximab following failure of antiviral therapy for hepatitis $C$ virusasscociatedcryoglobulinemicvasculitis. Arthritis Rheum. 2012; 64(3):835-42

4. Gragnani L, Visentini M, Fognani E, Urraro T, De Santis A, Petraccia $\mathrm{L}$, et al. Prospective study of guideline-tailored therapy with direct-acting antivirals for hepatitis $C$ virus-associated mixed cryoglobulinemia. Hepatology 2016; 64(5):1473-82.

5. Emery JS, Kuczynski M, La D, AlmarzooqiS, Kowgier M, Shah H, et al.: Efficacy and safety of direct acting antivirals for the treatment of mixed cryoglobulinemia. Am J Gastroenterol. 2017;112(8):1298-1308. 
6. Jennette JC, Falk RJ, Bacon PA,Basu N, Cid MC, Ferrario F, et al 2012 Revised International Chapel Hill Consensus Conference Nomenclature of Vasculitides.Arthritis Rheum. 2013;65(1):1-11.

7. Mukhtyar C, Lee R, Brown D, Carruthers D, Dasgupta B, Dubey S, et al. Modification and validation of the Birmingham Vasculitis Activity Score (version 3).Ann Rheum Dis. 2009;68(12):1827-32.

8. Brouet JC, Clauvel JP, Danon F, Klein M, Seligmann M. Biologic and clinical significance of cryoglobulins. A report of 86 cases. Am J Med. 1974;57(5):775-88.

9. Biasiotta A, Casato M, La Cesa S, Colantuono S, Di Stefano G, Leone $\mathrm{C}$, et al. Clinical, neurophysiological, and skin biopsy findings in peripheral neuropathy associated with hepatitis $\mathrm{C}$ virus-related cryogobulinemia. J Neurol. 2014;261(4):725-31.

10. Saadoun D, Thibault V, Si Ahmed SN, Alric L, Mallet M, Guillaud C et al. Sofosbuvir plus ribavirin for hepatitis $C$ virus-associated cryoglobulinaemia vasculitis: VASCUVALDIC STUDY.Ann Rheum Dis. 2016;75(10):1777-82.

11. Saadoun D, Resche-Rigon M, Thibault V, Piette JC, Cacoub P. Antiviral therapy for hepatitis $C$ virus-associated cryoglobulinemia vasculitis: a long term follow-up study. Arthritis Rheum. 2006;54(11):3696-706

12. Saadoun D, RescheRigon M, Pol S, Thibault V, Blanc F, Pialoux G, et al. PegIFN $\alpha /$ ribavirin/ protease inhibitor combination in severe hepatitis C virus-associated mixed cryoglobulinemiavasculitis. J Hepatol 2015;62(1):24-30.

13. Saadoun D, Pol S, Ferfar Y, Alric L, Hezode C, Si Ahmed SN, et al. Efficacy and Safety of Sofosbuvir plus Daclatasvir for Treatment of HCV-associated CryoglobulinemiaVasculitis. Gastroenterology 2017;153(1):49-52.

14. Gragnani L, Piluso A, Urraro T,Fabbrizzi A, Fognani E, Petraccia L, et al.Virological and Clinical Response to Interferon-Free Regimens in
Patients with HCV-Related Mixed Cryoglobulinemia: Preliminary Results of a Prospective Pilot Study. Curr Drug Targets, 2017;18(7): $772-85$.

15. Sollima S, Milazzo L, Peri AM, Torre A, Antinori S, Galli M. Persistent mixed cryoglobulinaemiavasculitis despite hepatitis $C$ virus eradication after interferon-free antiviral therapy. Rheumatology (Oxford). 2016;55(11):2084-85

16. Comarmond C, Garrido M, Pol S, Desbois AC, Costopoulos M, Le Garff-Tavernier M, et al. Direct-acting antiviral therapy restores immune tolerance to patients with hepatitis $C$ virus-induced cryoglobulinemiavasculitis. Gastroenterology. 2017;152(8):2052-62.

17. Bonacci M, Lens S, Londono MC, Mariño Z, Cid MC, Ramos-Casals $M$, et al. Virologic, clinical, and immune response outcomes of patients with hepatitis $C$ virus-associatedcryoglobulinemia treated with direct-acting antivirals. ClinGastroenterolHepatol. 2017;15(4): 575-83.

18. Cornella SL, Stine JG, Kelly V, Caldwell SH, Shah NL. Persistence of mixed cryoglobulinemia despite cure of hepatitis $C$ with new oral antiviral therapy including direct-acting antiviral Sofosbuvir: A case series. Postgrad Med. 2015;127(4):413-7.

19. Giannelli F, Moscarella S, Giannini C, Caini P, Monti M, Gragnani L, et al. Effect of antiviral treatment in patients with chronic HCV infection and t(14;18) translocation. Blood. 2003;102(4):1196-201.

20. Giannini C, Petrarca A, Monti M, Arena U, Caini P, Solazzo V, et al. Association between persistent lymphatic infection by hepatitis $\mathrm{C}$ virus after antiviral treatment and mixed cryoglobulinemia. Blood. 2008;111(5):2943-45

21. Landau DA, Saadoun D, Halfon P, Martinot-Peignoux M, Marcellin P, Fois $E$, et al. Relapse of hepatitis $C$ virus-associated mixed cryoglobulinemiavasculitis in patients with sustained viral response. Arthritis Rheum. 2008;58(2):604-11. 